\title{
Molecular Genetic Mechanisms of Hereditary Spherocytosis: Current Perspectives
}

\author{
Ben-Jin He Lin Liao Zeng-Fu Deng Yi-Feng Tao Yu-Chan Xu Fa-Quan Lin \\ Department of Clinical Laboratory, The First Affiliated Hospital of Guangxi Medical University, Nanning, China
}

\section{Keywords}

Erythrocyte membrane protein · Gene mutation .

Hereditary spherocytosis

\begin{abstract}
With the widespread use of genetic diagnostic technologies, many novel mutations have been identified in hereditary spherocytosis (HS)-related genes, including SPTA1, $S P T B, A N K 1, S L C 4 A 1$, and EPB42. However, mutations in HSrelated genes are dispersed and nonspecific in the diagnosis of some HS patients, indicating significant heterogeneity in the molecular deficiency of HS. It is necessary to provide the molecular and genetic characteristics of these 5 genes for clinicians to examine HS. Here, we reviewed the recent proposed molecular genetic mechanisms of HS.
\end{abstract}

(c) 2018 S. Karger AG, Basel

\section{Introduction}

Hereditary spherocytosis (HS) is a common type of hereditary hemolytic anemia, with wide heterogeneity in the severity of its clinical symptoms, membrane protein defects, and genetic patterns. HS is characterized by anemia, jaundice, splenomegaly, and cholelithiasis. In the primary pathogenic mechanism of HS, dysregulation or

\section{KARGER}

(๑) 2018 S. Karger AG, Basel

E-Mail karger@karger.com

www.karger.com/aha abnormal quantities of erythrocyte membrane protein can decrease the stability and deformability of erythrocytes and increase their osmotic fragility, causing them to break easily and cause hemolysis.

There are 5 genes associated with HS, including $\alpha$-spectrin (SPTA1), $\beta$-spectrin (SPTB), ankyrin (ANK1), band 3 (SLC4A1), and protein 4.2 (EPB42), that are involved in the interaction between the erythrocyte membrane and the lipid bilayer. Mutations in $\geq 1$ HS-related genes can cause membrane protein deficiency $[1,2]$, leading to HS. The mutations in these 5 genes differ between countries, so HS can easily be misdiagnosed and overlooked in the clinic [3-5].

We analyzed the pathogenic characteristics and genetic mechanisms of HS in the literature, focusing on its molecular genetics, in order to provide references for genetic counseling, prenatal diagnosis, and future research directions.

\section{Molecular Genetic Mechanisms of Five HS-Related Genes}

ANK1

Ankyrin-1, encoded by ANK1, is a major protein of erythrocytes, and it anchors transmembrane proteins to the cell membrane skeleton through band 3 , spectrin, and 


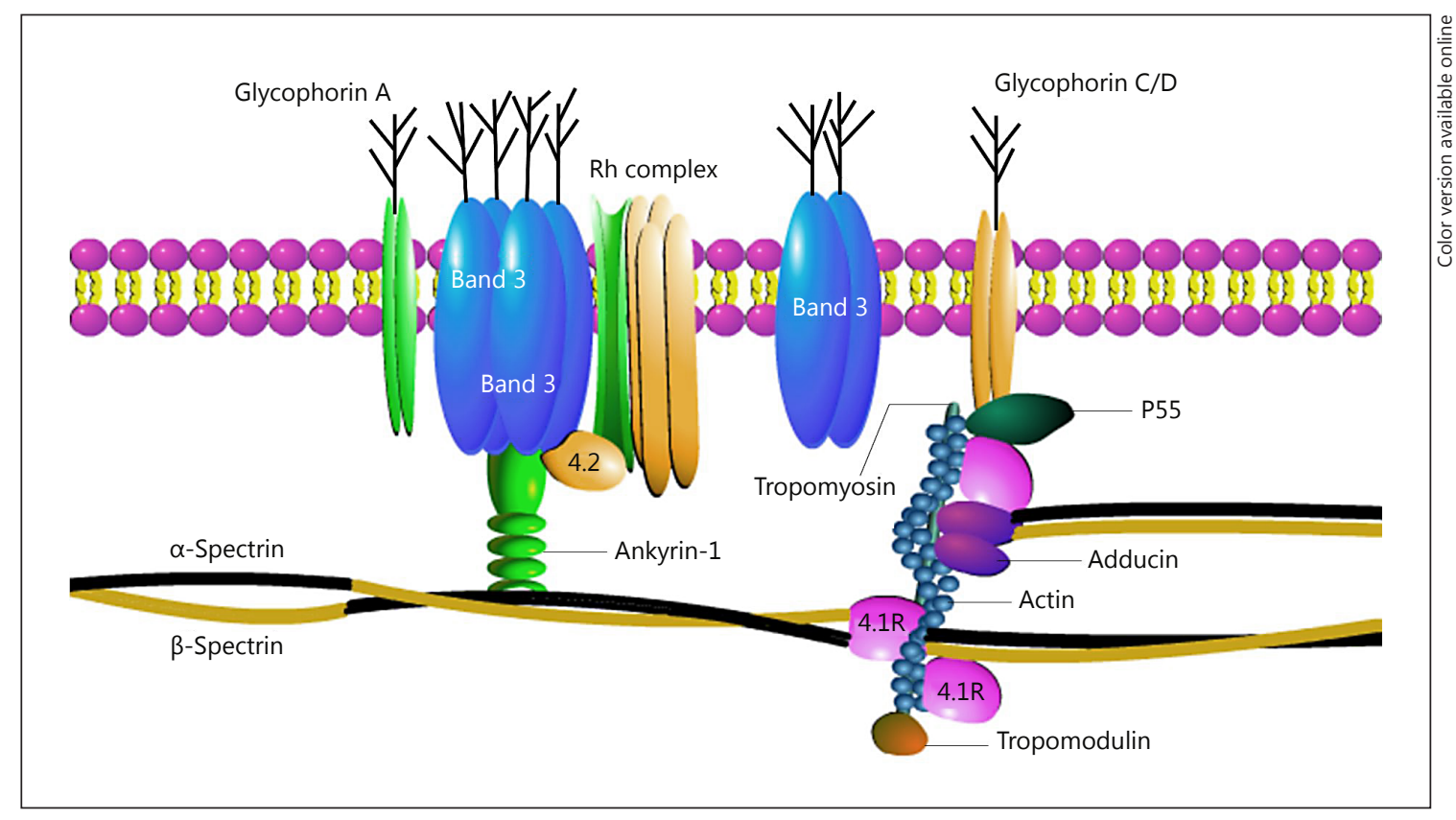

Fig. 1. Schematic presentation of erythrocyte membrane proteins. The erythrocyte membrane proteins regulating the elasticity and deformability in a vertical direction are band 3, ankyrin-1, protein 4.2, spectrin, and Rh complex. Those regulating the properties in a horizontal direction include spectrin, protein 4.1R, actin, adducin, tropomodulin, tropomyosin, and p55.

protein 4.2 (Fig. 1). More than 60 mutations have been identified in ANK1 in HS patients, including 7 missense mutations [2]. However, not all polymorphisms alter the expression or levels of ANK1.

Park et al. [6] verified that heterozygous ANK1 mutations are the most common mutations in these 5 HS-related genes, accounting for $52 \%$ of all Korean HS patients; the mutation types are primarily frameshift, nonsense, and splice site mutations. ANK1 heterozygous mutations account for approximately $31 \%$ of all Japanese HS patients [7], suggesting that the proportions of heterozygous mutations in ANK1 differ in HS patients between countries. Gallagher et al. [8] reported that the same site in exon 14 of $A N K 1$ was mutated in 3 HS patients from different countries and genetic backgrounds, causing a frameshift mutation and premature chain termination. The resulting mutant protein is called Ankyrin Florianópolis and is associated with severe HS. This mutation has been helpful in studying the molecular genetic mechanisms of HS, but no new cases at this site have been reported.

Approximately half of all HS patients are associated with mutations in ANK1 [9]. The genetic pattern of most HS patients with ANK1 mutations is autosomal domi- nant, but autosomal recessive inheritance has occurred in several such patients. Mutations in ANK1 are unique to an individual or an entire kindred $[2,10,11]$, and common mutation sites in a family can be inherited. Miya et al. [12] identified a 3.7-Mb deletion from 8 p11.2 in a 19-month-old HS patient with Kallmann syndrome; the deleted region included $A N K 1$, but no mutation was found in any exons of $A N K 1$. It was presumed that HS was induced by haploinsufficiency of $A N K 1$, demonstrating that there is a complex pathogenic relationship between ANK1 and HS.

Many studies [13-17] have demonstrated that ANK1 mutant mice have clinical phenotypes to those of humans with HS, and have confirmed that ANK1 mutations play an important role in the pathogenesis of HS in mice. Several Chinese case reports have identified ANK1 mutation sites [18-20]; these are sporadic and differ among cases.

\section{SLC4A1}

$S L C 4 A 1$ encodes 2 protein isomers, the $\mathrm{Cl}-/ \mathrm{HCO}_{3}$-anionic exchange transporter 1 in erythrocytes (band 3/ eAE1) and a truncated form of anionic exchange transporter 1, which is expressed in $\alpha$-intercalated kidney cells (kAE1). A variety of mutations in human SLC4A1 can 
cause 2 diseases [21], HS and distal renal tubular acidosis, due to a loss of erythrocyte membrane deformability, or a deficiency in urine acidification, respectively. Band 3 deficiency is often inherited in a dominant manner, occurring in approximately $33 \%$ of HS patients [22]. The chief types of SLC4A1 mutations are missense and frameshift.

Studies on the association between SLC4A1 mutations and HS have reported that these occur primarily in exons, which can lead to truncated or unstable band 3, disrupting its function [23-25]. Moreover, mutations can arise in introns, resulting in abnormal mRNA processing or a premature termination codon [23-25]. SLC4A1 mutations also cause distal renal tubular acidosis, which has been observed along with HS in the same patient [26,27].

Chu et al. [28] found a TGC>TGG mutation in exon 13 and a GGC>GAC mutation in exon 17 of SLC4A1 in an HS patient with distal renal tubular acidosis. The mutation in exon 13 was detected in his father and that in exon 17 in his mother. These findings indicate that these mutations in SLC4A1 induce the combination of HS and distal renal tubular acidosis and also that the mutations are inherited.

There are only a few reports on SLC4A1 mutations in HS patients in China. We studied an SLC4A1 mutation in a family [29] but did not find any reported pathogenic mutations, such as c.1582C $>\mathrm{T}$, c. $2624 \mathrm{C}>\mathrm{T}, \mathrm{c} .2623 \mathrm{C}>\mathrm{G}$, and c. $2623 \mathrm{~A}>\mathrm{G}$, indicating that SLC4A1 mutation sites are diverse and appear in other exons or introns. Another of our studies confirmed that the majority of HS patients in China suffer from band 3 deficiency, and we verified the existence of sporadic mutation sites in SLC4A1 in HS patients from various families in exons and introns [30].

The mutation sites in SLC4A1 vary in HS patients, but most are concentrated in exons. SLC4A1 mutations are not specific to HS, so the presence of distal renal tubular acidosis, or a combination of this with HS should be considered. Even if there is a mutation in SLC4A1, the clinical data and other relevant laboratory results of patients must be analyzed further.

\section{SPTA1}

a-Spectrin, encoded by SPTA1, plays a major role in the shape and deformability of erythrocytes. $\alpha$-Spectrin deficiency might cause HS, accounting for approximately $5 \%$ of HS patients. It is transmitted primarily by autosomal recessive inheritance, and mutations in SPTA1 are mainly splice site mutations $[22,31,32]$.

Wichterle et al. [33] found compound heterozygous mutations in 2 alleles of SPTA1 in a single patient with severe spherocytic hemolytic anemia but no family history of HS: aLEPRA ( $\mathrm{C} \rightarrow \mathrm{T}$ at position 99 in intron 30, leading to a frameshift mutation and a significant decrease in $\alpha$-spectrin synthesis) and $\alpha$ PRAGUE $(A \rightarrow G$ at position 2 in intron 36 , leading to a frameshift mutation and truncated $\alpha$-spectrin). It is presumed that aLEPRA is a widely distributed allele that is associated with the pathogenesis of HS and a lack of spectrin.

Delaunay et al. [34] identified compound heterozygous mutations in 2 alleles in a family in which the siblings had severe HS, aLEPRA (from the mother), and aLELY-Bicêtre (from the father; resulting in $\mathrm{G} \rightarrow \mathrm{A}$ at position 2377 in exon 51 of the lowly expressed polymorphic allele, aLELY, essentially a null mutation of a synthetic nonfunctional protein). The $\alpha$-chain yield of aLEPRA and aLELY-Bicêtre is 16 and $0 \%$ of the normal amount, respectively. Thus, total $\alpha$-spectrin synthesis reaches up to $8 \%$ of normal production. Only a reduction in $\alpha$-spectrin expression to $<25 \%$ of the normal yield can cause spherocytosis.

Bogardus et al. [35] found a $\mathrm{C} \rightarrow \mathrm{T}$ homozygous mutation in exon 19 of SPTA 1 in a severe transfusion-dependent HS proband; this mutation converts arginine 891 to stop codon. His mother was heterozygous for the R891X mutation. By array-based comparative genomic hybridization, uniparental disomy was partially identified from the mother on chromosome 1 of the proband, suggesting that this deleterious mutation leads to HS and raising the possibility that uniparental disomy is a pathogenic mechanism of HS.

Christensen et al. [36] verified that SPTA1 mutations are also present in patients with hereditary elliptocytosis, reporting 2 new mutations. There have been no reports of mutations in SPTA1 in HS patients in China.

aLEPRA mutations are common in HS patients with SPTA1 mutations [22, 32], but the other new mutations in SPTA1 continue to be reported, showing its heterogeneity and also indicating that such mutations are not unique to HS; they can be found in hereditary elliptocytosis. The interaction among mutations in the same gene can lead to a variety of clinical phenotypes, eliciting inconsistent phenotypes. Therefore, in the diagnosis of HS, we should combine clinical, erythrocyte morphological, biochemical, and genomic data.

\section{SPTB}

$\beta$-Spectrin, encoded by SPTB, plays an important role in the stability of the erythrocyte membrane. In normal human erythrocytes, $\alpha$-spectrin is synthesized at rates 3-4 times that of $\beta$-spectrin. Therefore, a mutation in an
$\mathrm{He} / \mathrm{Liao} / \mathrm{Deng} / \mathrm{Tao} / \mathrm{Xu} / \mathrm{Lin}$ 
Table 1. Molecular and genetic characteristics of 5 erythrocyte membrane protein genes

\begin{tabular}{lllll}
\hline Gene & $\begin{array}{l}\text { Membrane } \\
\text { protein }\end{array}$ & Prevalent mutations & Heredity & $\begin{array}{l}\text { Associated } \\
\text { disease }\end{array}$ \\
\hline ANK1 & Ankyrin-1 & frameshift, nonsense, splicing, novel mutations & AD, AR & HS \\
SLC4A1 & Band 3 & missense, frameshift, polymorphism & AD & HS, dRTA \\
SPTA1 & a-Spectrin & SpaLEPRA allele, splicing, frameshift & AR & HS, HE, HPP \\
SPTB & B-Spectrin & splicing, frameshift, nonsense, novel mutations & AD & HS, HE, HPP \\
EBP42 & Protein 4.2 & missense, nonsense & AR & HS \\
\hline
\end{tabular}

$\mathrm{AD}$, autosomal dominant; AR, autosomal recessive; dRTA, distal renal tubular acidosis; LEPRA, lowexpression allele Prague; HE, hereditary elliptocytosis; HPP, hereditary pyropoikilocytosis.

allele of $\beta$-spectrin can lead to erythrocytosis; if both alleles are mutated, the incidence of HS increases [22]. $\beta$-spectrin deficiency is usually inherited in an autosomal dominant manner, accounting for approximately 15$30 \%$ of HS patients in the northern European population [22]. Heterozygous mutations in SPTB represent approximately $25 \%$ of HS patients in the USA and Europe [37]. The common mutation types in SPTB include splice site, frameshift, and nonsense mutations, often leading to defects in mRNA processing and truncated $\beta$-spectrin [38].

Previous studies $[6,36,38]$ have shown that SPTB mutations are associated with HS, but findings vary with regard to the site of the mutation. In families with HS, researchers have found a common mutation site in SPTB that is specific to each family, indicating that this site is associated with the pathogenesis of HS and is inherited. Garbarz et al. [39] detected $\mathrm{G} \rightarrow \mathrm{C}$ in exon 3 of SPTB in all members of a dominant HS family; this mutation can severely reduce the utilization of the $5^{\prime}$ splice site, causing aberrant splicing of mRNA with intron 3 retention and ultimately decreasing $\beta$-spectrin mRNA levels. Boguslawska et al. [40] found a novel heterozygous mutation, 466insG, in exon 11 of SPTB, in all members of a Polish HS family, and they concluded that SPTB undergoes monoallelic expression, resulting in spectrin deficiency. Mutations in SPTB have also been identified in Chinese HS patients [19], but there are no reports on any of them, suggesting that they are novel and specific to HS patients.

\section{EPB42}

Protein 4.2, encoded by $E P B 42$, is a key protein of the erythrocyte membrane and an ATP-binding protein that regulates the relationship between band 3 and ankyrin; it also has an important role in the regulation of the shape and mechanical properties of erythrocytes. Protein 4.2 deficiency is primarily recessive. Genetic variations in
$E P B 42$ are primarily missense and nonsense mutations (Table 1). EPB42 mutations are generally found in the Japanese population [32]. They generate variants in protein 4.2 , including protein 4.2 Lisboa (265delG), protein 4.2 Komatsu (D175Y), protein 4.2 Nippon (A142T), and protein 4.2 Shiga (R317C). They cause protein 4.2 deficiency and are strongly associated with HS.

EPB42 mutation-induced HS has also been reported in other populations. Beauchamp-Nicoud et al. [41] detected 949delG in exon 7 of EPB42 of a gypsy; it produces protein 4.2 Nancy and is associated with HS. Bruce et al. [42] reported a 41-bp frameshift loss in protein $4.2 \mathrm{cDNA}$ of a Pakistani HS proband, probably leading to the truncated protein 4.2 hammersmith. By conducting genomic DNA sequencing, they found a homozygous mutation, $1747 \mathrm{G}>\mathrm{T}$, in exon 11 of EPB42, and the proband's mother was heterozygous for mutations. Maciag et al. [43] observed that the relative mRNA levels of EPB 42 were decreased by approximately $45 \%$ in a Polish $\alpha$-thalassemia patient with a protein 4.2 mutation. They identified 2 mutations by sequencing: G1701A in exon $10 \mathrm{EPB} 42$, leading to an A567T mutation, and IVS2nt $+6 \mathrm{~T}>\mathrm{A}$ in $E P B 42$, decreasing splice site activity and leading to mRNA instability.

EPB42 mutations in HS patients are rare in China. We found a single-nucleotide polymorphism (SNP), c.329C $>\mathrm{T}$ (Ser $10 \mathrm{Leu}$ ), in exon 1 of EPB42 in an HS patient and in his mother, as well as other mutations in ANK1 [18]. SNPs may affect the stability of a protein or its mRNA levels [44], suggesting that the SNP in EPB42 is involved in the pathogenesis of HS.

Thus, mutations in EPB42 are linked to HS. EPB42 mutation-induced HS has been reported in several countries, but the mutation sites vary. Multiple mutation sites in the same gene or simultaneous mutations in several HS-related genes can produce complex molecular genetic mechanisms in HS. 


\section{Summary and Prospects}

HS is a common type of hereditary hemolytic anemia. The prevalence of HS in North America and northern Europe is $1 / 2,000$ [22, 32]. Wang et al. [45] measured the prevalence of HS in China from 1978 to 2013 using DisMod-II software; it was $1.27 / 100,000$ in males and $1.49 / 100,000$ in females. Historically, experimental methods, such as peripheral blood smear, red blood cell osmotic fragility test, acidified glycerin hemolysis test, and SDS-PAGE, have had low sensitivity and specificity. HS has therefore been easily missed, and patients have been diagnosed as having G6PD deficiency or another type of autoimmune hemolytic anemia [4]. These data in China need to be confirmed. In the USA and Europe, HS patients primarily bear ANK1 mutations, accounting for $40-65 \%$ of all HS patients; in Japan, HS patients generally harbor EPB 42 mutations, representing $40-50 \%$ of all patients with HS [22]; and in South Korea, most HS patients (52\%) have ANK1 mutations [6].

Erythrocyte morphology, a blood analyzer, or SDSPAGE are used to diagnose sporadic HS in China. In recent years, HS-related gene mutation sites have been reported, but these sites are sporadic and diverse. We found that most Chinese HS patients are affected by band 3 deficiency [30], but because of the small number of reported cases, it is necessary to collect more data to determine the actual rates of erythrocyte membrane protein deficiency in Chinese HS patients.

The guidelines for the diagnosis and management of HS state that ANK1, SLC4A1, or SPTB mutations are common in autosomal dominant HS [32]. New mutations in $A N K 1$ and SPTB can be found in most recessive HS patients [32]. Therefore, research on HS continues to face new challenges. Analyzing reported HS cases and their molecular genetic mechanisms can provide the basis for genetic counseling, prenatal and postnatal care, prenatal diagnosis, and future research into HS.

With the rapid development and wide application of gene diagnostic technologies, the detection rate of HS cases is increasing. Sequencing results have shown that $\geq 1$ of the genes that we have discussed, i.e., SPTA1, SPTB, $A N K 1, S L C 4 A 1$, and EPB42, are mutated. Most of these novel mutations occur in exons, but several arise in introns, suggesting that intronic mutations also play an important role in the pathogenesis of HS. However, there is no hotspot mutation in HS; most mutations are sporadic and specific to individual patients or their families.

A single heterozygous (or homozygous) or compound heterozygous mutation has occurred in the same gene in
HS patients, and mutations in $\geq 2$ related genes can also develop. The mutation sites therefore present with tremendous heterogeneity. In some cases, the synergistic or inhibitory effects of multiple mutations in related genes can lead to a complex pathogenesis of HS. HS, combined with other diseases, such as $\beta$-thalassemia and Gilbert syndrome [46, 47], can lead to inconsistent HS genotypes and phenotypes, causing high rates of missed diagnoses or even misdiagnoses in clinical HS cases.

The guidelines for the diagnosis and management of HS suggest that HS can be diagnosed using molecular detection of related genes [32]; no further examination is required. This approach may be suitable for some HS patients with mild clinical symptoms and can be considered a new standard for HS diagnosis. Nevertheless, recent studies have verified that mutations in SLCAA1 and SPTA 1 are not specific to HS patients [4, 48, 49]. To identify different types of hemolytic anemia and hepatitis, clinical histories and laboratory tests are needed $[3,4,48-$ 51]. Ribeiro et al. [52] reported that, in the case of some mutations that can be inherited and lead to severe HS, genetic counseling and prenatal diagnosis can play an extremely important role in prenatal and postnatal care. Thus, if $\geq 2$ members of a family with HS are found to have the same mutation in the same gene, this suggests that the mutation site is hereditary. This is important when studying the molecular genetic mechanisms of HS and assessing the risk of HS for other members or descendants of the family, and can guide the future of precision medical care.

\section{Acknowledgments}

This study was funded by the National Natural Science Foundation of China, grant No. 81360263.

\section{Disclosure Statement}

We declare that we have no conflicts of interest.

\section{References}

1 Boguslawska DM, Heger E, Sikorski AF: Molecular mechanism of hereditary spherocytosis. Pol Merkur Lekarski 2006;20:112-116.

2 Boguslawska DM, Heger E, Listowski M, Wasinski D, Kuliczkowski K, Machnicka B, Sikorski AF: A novel L1340P mutation in the ANK1 gene is associated with hereditary spherocytosis? Br J Haematol 2014;167:269271.
$\mathrm{He} / \mathrm{Liao} / \mathrm{Deng} / \mathrm{Tao} / \mathrm{Xu} / \mathrm{Lin}$ 
3 Tao YF, Deng ZF, Liao L, Qiu YL, Deng XL, Chen WQ, Lin FQ: Evaluation of a flow-cytometric osmotic fragility test for hereditary spherocytosis in Chinese patients. Acta Haematol 2016;135:88-93.

4 Deng Z, Liao L, Yang W, Lin F: Misdiagnosis of two cases of hereditary spherocytosis in a family and review of published reports. Clin Chim Acta 2015;441:6-9.

5 Zhong HX, Zhang LJ: Analysis on long term misdiagnosis of hereditary spherocytosis. Int J Lab Med 2015;36:3581-3585.

6 Park J, Jeong DC, Yoo J, Jang W, Chae H, Kim J, Kwon A, Choi H, Lee JW, Chung NG, Kim M, Kim Y: Mutational characteristics of ANK1 and SPTB genes in hereditary spherocytosis. Clin Genet 2016;90:69-78.

7 Nakanishi H, Kanzaki A, Yawata A, Yamada $\mathrm{O}$, Yawata Y: Ankyrin gene mutations in Japanese patients with hereditary spherocytosis. Int J Hematol 2001;73:54-63.

8 Gallagher PG, Ferreira JD, Costa FF, Saad ST, Forget BG: A recurrent frameshift mutation of the ankyrin gene associated with severe hereditary spherocytosis. Br J Haematol 2000; 111:1190-1193.

9 Gallagher PG: Hematologically important mutations: ankyrin variants in hereditary spherocytosis. Blood Cells Mol Dis 2005;35: 345-347.

10 Han JH, Kim S, Jang H, Kim SW, Lee MG, Koh $\mathrm{H}$, Lee JH: Identification of a novel p.Q1772X ANK1 mutation in a Korean family with hereditary spherocytosis. PLoS One 2015;10:e0131251.

11 Gundel F, Eber S, Heep A: A new ankyrin mutation (ANK1 EXON E9X) causing severe hereditary spherocytosis in the neonatal period. Ann Hematol 2011;90:231-232.

12 Miya K, Shimojima K, Sugawara M, Shimada S, Tsuri H, Harai-Tanaka T, Nakaoka S, Kanegane H, Miyawaki T, Yamamoto T: A de novo interstitial deletion of 8 p11.2 including ANK1 identified in a patient with spherocytosis, psychomotor developmental delay, and distinctive facial features. Gene 2012;506: 146-149.

13 Gallagher PG, Sabatino DE, Basseres DS, Nilson DM, Wong C, Cline AP, Garrett LJ, Bodine DM: Erythrocyte ankyrin promoter mutations associated with recessive hereditary spherocytosis cause significant abnormalities in ankyrin expression. J Biol Chem 2001;276:41683-41689.

14 Gallagher PG, Steiner LA, Liem RI, Owen AN, Cline AP, Seidel NE, Garrett LJ, Bodine DM: Mutation of a barrier insulator in the human ankyrin-1 gene is associated with hereditary spherocytosis. J Clin Invest 2010;120:44534465.

15 Huang H, Zhao P, Arimatsu K, Tabeta K, Yamazaki K, Krieg L, Fu E, Zhang T, Du X: A deep intronic mutation in the ankyrin-1 gene causes diminished protein expression resulting in hemolytic anemia in mice. G3 (Bethesda) 2013;3:1687-1695.
16 Hughes MR, Anderson N, Maltby S, Wong J, Berberovic Z, Birkenmeier CS, Haddon DJ, Garcha K, Flenniken A, Osborne LR, Adamson SL, Rossant J, Peters LL, Minden MD, Paulson RF, Wang C, Barber DL, McNagny KM, Stanford WL: A novel ENU-generated truncation mutation lacking the spectrinbinding and C-terminal regulatory domains of Ank1 models severe hemolytic hereditary spherocytosis. Exp Hematol 2011;39:305320, 320.e301-e302.

17 Kildey K, Flower RL, Tran TV, Tunningley R, Harris J, Dean MM: Characterization of ENU-induced mutations in red blood cell structural proteins. Comput Struct Biotechnol J 2013;6:e201303012.

18 Liao L, Qiu YL, Deng ZF, Huang J, Lin FQ: Gene mutation analysis of a patient with hereditary spherocytosis. Maternal Child Health Care China 2013;28:6002-6004.

19 Cao YN, Lin L, Wu X, Wang XF, Ding QL, Chen Y, Cheng S, Wang HL: Study on molecular pathogenesis of three cases with hereditary spherocytosis. Chin J Blood Transfusion 2013;26:948-949.

20 Jiang M, Lu J, Zhong Y, Wang Y, Yang C: Identification of a novel ANK1 gene mutation in a newborn with hereditary spherocytosis. Zhonghua Yi Xue Yi Chuan Xue Za Zhi 2016; 33:44-47.

21 Tanner MJ: Band 3 anion exchanger and its involvement in erythrocyte and kidney disorders. Curr Opin Hematol 2002;9:133-139.

22 Perrotta S, Gallagher PG, Mohandas N: Hereditary spherocytosis. Lancet 2008;372: 1411-1426.

23 Camacho-Torres AL, Sanchez-Lopez JY, Mesa-Cornejo VM, Ibarra B, Perea-Diaz FJ: Polymorphism analysis of G199A, Ncol in ANK1 and Memphis I in SLC4A1 genes in Mexican healthy individuals and subjects affected with hereditary spherocytosis. Gac Med Mex 2006;142:435-437.

24 Sanchez-Lopez JY, Camacho-Torres AL, Ibarra B, Tintos JA, Perea FJ: Analysis of the SLC4A1 gene in three Mexican patients with hereditary spherocytosis: report of a novel mutation. Genet Mol Biol 2010;33:9-11.

25 Van Zwieten R, Francois JJ, Van Leeuwen K, Van Wesel AC, Van Bruggen R, Van Solinge WW, Roos D, Verhoeven AJ, Van Wijk R: Hereditary spherocytosis due to band 3 deficiency: 15 novel mutations in SLC4A1. Am J Hematol 2013;88:159-160.

26 Takeuchi T, Hattori-Kato M, Okuno Y, Kanatani A, Zaitsu M, Mikami K: A single nucleotide polymorphism in kidney anion exchanger 1 gene is associated with incomplete type 1 renal tubular acidosis. Sci Rep 2016;6:35841.

27 Kager L, Bruce LJ, Zeitlhofer P, Flatt JF, Maia TM, Ribeiro ML, Fahrner B, Fritsch G, Boztug $\mathrm{K}$, Haas OA: Band 3 nullVIENNA, a novel homozygous SLC4A1 p.Ser477X variant causing severe hemolytic anemia, dyserythropoiesis and complete distal renal tubular acidosis. Pediatr Blood Cancer 2017, DOI: 10.1002/ pbc.26227.
28 Chu C, Woods N, Sawasdee N, Guizouarn H, Pellissier B, Borgese F, Yenchitsomanus PT, Gowrishankar M, Cordat E: Band 3 Edmonton I, a novel mutant of the anion exchanger 1 causing spherocytosis and distal renal tubular acidosis. Biochem J 2010;426:379-388.

29 Qiu YL: Gene mutation analysis in kindred with hereditary spherocytosis (dissertation). Nanning (GX): Guangxi Medical University; 2011.

30 Yang W: SLC4A1 mutations in Chinese pedigrees with hereditary spherocytosis (dissertation). Nanning, Guangxi Medical University, 2016.

31 Iolascon A, Avvisati RA: Genotype/phenotype correlation in hereditary spherocytosis. Haematologica 2008;93:1283-1288.

32 Bolton-Maggs PH, Langer JC, Iolascon A, Tittensor P, King MJ; General Haematology Task Force of the British Committee for Standards in Haematology: Guidelines for the diagnosis and management of hereditary spherocytosis 2011 update. Br J Haematol 2012;156:37-49.

33 Wichterle H, Hanspal M, Palek J, Jarolim P: Combination of two mutant alpha spectrin alleles underlies a severe spherocytic hemolytic anemia. J Clin Invest 1996;98:2300-2307.

34 Delaunay J, Nouyrigat V, Proust A, Schischmanoff PO, Cynober T, Yvart J, Gaillard C, Danos O, Tchernia G: Different impacts of alleles alphaLEPRA and alphaLELY as assessed versus a novel, virtually null allele of the SPTA1 gene in trans. Br J Haematol 2004;127: 118-122.

35 Bogardus H, Schulz VP, Maksimova Y, Miller BA, Li P, Forget BG, Gallagher PG: Severe nondominant hereditary spherocytosis due to uniparental isodisomy at the SPTA1 locus. Haematologica 2014;99:e168-e170.

36 Christensen RD, Agarwal AM, Yaish HM, Reading NS, O'Brien EA, Prchal JT: Three novel spectrin variants in jaundiced neonates. Clin Pediatr 2018;57:19-26.

37 Hassoun H, Vassiliadis JN, Murray J, Njolstad PR, Rogus JJ, Ballas SK, Schaffer F, Jarolim P, Brabec V, Palek J: Characterization of the underlying molecular defect in hereditary spherocytosis associated with spectrin deficiency. Blood 1997;90:398-406.

38 Maciag M, Plochocka D, Adamowicz-Salach A, Burzynska B: Novel beta-spectrin mutations in hereditary spherocytosis associated with decreased levels of mRNA. Br J Haematol 2009; 146:326-332.

39 Garbarz M, Galand C, Bibas D, Bournier O, Devaux I, Harousseau JL, Grandchamp B, Dhermy D: A $5^{\prime}$ splice region $\mathrm{G}->$ C mutation in exon 3 of the human beta-spectrin gene leads to decreased levels of beta-spectrin mRNA and is responsible for dominant hereditary spherocytosis (spectrin GuemenePenfao). Br J Haematol 1998;100:90-98.

40 Boguslawska DM, Heger E, Machnicka B, Skulski M, Kuliczkowski K, Sikorski AF: A new frameshift mutation of the beta-spectrin gene associated with hereditary spherocytosis. Ann Hematol 2017;96:163-165. 
41 Beauchamp-Nicoud A, Morle L, Lutz HU, Stammler P, Agulles O, Petermann-Khder R, Iolascon A, Perrotta S, Cynober T, Tchernia G, Delaunay J, Baudin-Creuza V: Heavy transfusions and presence of an anti-protein 4.2 antibody in $4.2(-)$ hereditary spherocytosis (949delG). Haematologica 2000;85:19-24.

42 Bruce LJ, Ghosh S, King MJ, Layton DM, Mawby WJ, Stewart GW, Oldenborg PA, Delaunay J, Tanner MJ: Absence of CD47 in protein 4.2-deficient hereditary spherocytosis in man: an interaction between the Rh complex and the band 3 complex. Blood 2002;100: 1878-1885.

43 Maciag M, Adamowicz-Salach A, Siwicka A, Spychalska J, Burzynska B: The use of realtime PCR technique in the detection of novel protein 4.2 gene mutations that coexist with thalassaemia alpha in a single patient. Eur J Haematol 2009;83:373-377.
44 Boguslawska DM, Heger E, Baldy-Chudzik K, Zagulski M, Maciejewska M, Likwiarz A, Sikorski AF: (AC)n microsatellite polymorphism and 14-nucleotide deletion in exon 42 ankyrin-1 gene in several families with hereditary spherocytosis in a population of SouthWestern Poland. Ann Hematol 2006;85:337339.

45 Wang C, Cui Y, Li Y, Liu X, Han J: A systematic review of hereditary spherocytosis reported in Chinese biomedical journals from 1978 to 2013 and estimation of the prevalence of the disease using a disease model. Intractable Rare Dis Res 2015;4:76-81.

46 Ben Hamouda H, Mahjoub B, Soua H, Laradi S, Miled A, Sfar MT: Neonatal expression of beta-thalassemia trait associated with hereditary spherocytosis in two monozygotic twins. Arch Pediatr 2017;24:126-130.

47 Lee HJ, Moon HS, Lee ES, Kim SH, Sung JK, Lee BS, Jeong HY, Lee HY, Eu YJ: A case of concomitant Gilbert's syndrome and hereditary spherocytosis. Korean J Hepatol 2010;16: 321-324.
48 Liao L, Deng ZF, Qiu YL, Chen P, Chen WQ, Lin FQ: Values of mean cell volume and mean sphered cell volume can differentiate hereditary spherocytosis and thalassemia. Hematology 2014;19:393-396.

49 Xu Y, Yang W, Liao L, Deng Z, Qiu Y, Chen W, Lin F: Mean reticulocyte volume: a specific parameter to screen for hereditary spherocytosis. Eur J Haematol 2016;96:170-174.

50 Lin FQ, Tang JG, Ju Y, Qiu YL: Diagnostic value of MSCV in hereditary spherocytosis. J Pract Med 2010;26:2537-2539.

51 Tao YF, Deng ZF, Liao L, Qiu YL, Chen WQ, Lin FQ: Comparison and evaluation of three screening tests of hereditary spherocytosis in Chinese patients. Ann Hematol 2015;94:747751

52 Ribeiro ML, Alloisio N, Almeida H, Gomes C, Texier P, Lemos C, Mimoso G, Morle L, BeyCabet F, Rudigoz RC, Delaunay J, Tamagnini $\mathrm{G}$ : Severe hereditary spherocytosis and distal renal tubular acidosis associated with the total absence of band 3. Blood 2000;96:1602-1604. 